\title{
Estado, políticas sociais e direitos sociais: descompasso do tempo atual
}

\section{State, social policies and social rights: mismatch of the current time}

\author{
Helena Lúcia Augusto Chaves ${ }^{a}$ \\ (D) https://orcid.org/0000-0003-3325-0893 \\ Vitória Régia Fernandes Gehlen ${ }^{a}$ \\ (D) https://orcid.org/0000-0002-8222-247X
}

\begin{abstract}
Resumo: $O$ artigo apresenta reflexão sobre o descompasso do tempo atual entre a perspectiva dos direitos sociais, as políticas públicas e a ação estatal. Compõe a reflexão discussão sobre os sentidos do público e a falência das políticas sociais e da sua função regulatória e protetiva, no que se refere ao enfrentamento das desigualdades sociais. O objetivo é evidenciar conquistas civilizatórias da humanidade e refletir sobre as políticas sociais, seus fundamentos e suas contradições.
\end{abstract}

Palavras-chave: Desigualdades sociais. Estado. Políticas sociais. Direitos sociais.

\begin{abstract}
The article presents a reflection on the current mismatch between the perspective of social rights, public policies and state action. It makes up the discussion about the public's senses and the failure of social policies and their regulatory and protective function, regarding the confrontation of social inequalities. The objective is to highlight the humanity civilizational achievements and to reflect about social policies, their foundations and their contradictions.
\end{abstract}

Keywords: Social differences. State. Social policies. Social rights.

\section{Introdução}

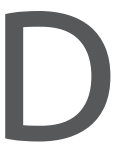

esde as duas décadas finais do século XX as ideias neoliberais dominam as práticas governamentais e se inscrevem nos processos político-culturais, configurando a política social com um perfil 
assistencialista. Ao longo desse período, propagou-se o discurso da necessidade de redução da atuação do Estado, prevalecendo a ideia de um mercado máximo e consolidando a concepção dominante de que o Estado não deve agir orientado pelos princípios e regras de justiça social. O resultado dessa lógica se expressa em uma profunda regressão no âmbito da proteção social e um aumento vertiginoso da precarização do trabalho, que vem intensificando a ampliação da pobreza, dificultando o acesso a renda e aprofundando as desigualdades sociais.

Por intermédio do planejamento de diferentes políticas públicas fragmentadas, o discurso neoliberal dos direitos sociais vai construindo o arcabouço, bordando o tecido e configurando o próprio sentido de injustiça, aprofundando as desigualdades sociais, precarizando o trabalho e as relações sociais, fundamentado pelo Estado neoliberal como contingência histórica e inevitável. O que vem sustentando tais discursos? Diferentemente dos discursos das ciências que se pretendem verificáveis, os discursos sobre direitos sociais e combate à pobreza aparecem como suportes de posições subjetivas, simulatório, opaco e interesseiro, cooptado pelo interesse econômico. É o discurso do poder, é um instrumento do poder dominante inserido nos mecanismos de mercado e nas engrenagens da tecnologia para gerar novos processos produtivos, aprofundando as desigualdades sociais (Leff, 2010). Discurso mascarado por muita retórica sobre liberdade individual, autonomia, livre mercado e livre-comércio que legitimou políticas públicas destinadas a restaurar e consolidar o poder da classe capitalista. Discurso que constrói o ideário de cidades globais, projetadas para o cenário internacional e disponíveis aos capitais externos, nas quais a privatização dos serviços vem engendrando novas formas de migrações, explorações e expropriações.

Fundamentadas nesses discursos, as políticas sociais no seu nascedouro, ainda no seu processo de concepção, são contaminadas por essa lógica e resultam em ações governamentais, que mais atendem aos interesses do capital do que do público-alvo prioritário das políticas. Nesse contexto, paradigmas são desfeitos e noções são ressignificadas, mudando o sentido histórico em que os termos foram gestados e ganharam compreensão, ampliação e adensamento. Daí os retrocessos ganham força e a reviravolta 
a tempos remotos compõe-se como marca do tempo presente, que se caracteriza por intolerância, obscurantismo, abuso de poder, unilateralismo, fundamentalismo e estreiteza de pensamento e de ação em todos os aspectos que compõem a ação estatal em todas as suas instâncias.

A reflexão aqui esboçada, resultante de pesquisas e estudos direcionados ao exercício da docência e à progressão funcional para titular da carreira docente, trata de aspectos conjunturais e estruturais que marcam o contexto histórico do tempo presente, tanto em nível nacional como internacional, e foi estruturada em três itens. No primeiro, são tratadas as noções de desigualdades, coesão social e desenvolvimento em perspectiva crítica, que objetiva elucidar os conceitos sobre os quais se erguem as políticas sociais no neoliberalismo e apontar a razão de seu descompasso nesse contexto. No segundo item, o enfoque é sobre os sentidos do público e as apropriações desses sentidos pela ordem vigente para salvaguarda do sistema. No terceiro item, o destaque é para as políticas sociais frente às desigualdades sociais e a sua inoperância tanto no aspecto regulatório, que inclui a coesão, como no aspecto protetivo, que abrange a integração.

O objetivo é manter ativa a discussão sobre o descompasso do tempo presente com as conquistas civilizatórias da humanidade e refletir sobre as políticas sociais, seus fundamentos e suas contradições, apontando aspectos do problema que podem se configurar em importantes instrumentos de conhecimento e intervenção profissional.

\section{Desigualdades e coesão social na noção de desenvolvimento}

A formulação de mecanismos e estratégias para gerar o chamado desenvolvimento tem sido uma constante nas receitas dos organismos internacionais e também nas políticas públicas planejadas pelo Estado. Tais mecanismos se encontram em um discurso permanente no qual, de diferentes formas, se alude ao objetivo de garantir melhor qualidade de vida às populações, em especial das que têm sido marginalizadas e excluídas dos recursos e bens advindos do citado desenvolvimento. O conceito 
de qualidade de vida passou a ser uma tônica na maioria dos discursos e políticas relacionadas às estratégias de desenvolvimentos local e nacional, constituindo-se parâmetro para o planejamento de ações governamentais direcionadas a interferir nos índices e indicadores sociais, tomados como medidas nos rankings internacionais entre as nações.

No sistema de comparação estatística, algumas noções se tornaram essenciais, como o termo desenvolvimento, que teve sua origem na segunda metade da década de 1940, sendo reformulado recorrentemente para ajustar-se à complexidade das sociedades atuais, em termos de dinâmica, problemática e demandas.

No início de 1990, o Programa das Nações Unidas para o Desenvolvimento (PNUD, 1990) introduziu o conceito de desenvolvimento humano, indicador social para mensurar o bem-estar individual das populações. Também o chamado desenvolvimento social passou a ser uma recomendação dos organismos internacionais, suscitando estratégias para a ação governamental. Daí a alusão ao desenvolvimento parecer significar um processo inclusivo, democrático, equitativo e justo.

Mas a desigualdade e a pobreza, resultantes da fragmentação social e da exclusão política, que caracterizam o sistema capitalista, continua sendo uma realidade persistente, subsistindo mesmo nos períodos de expansão econômica, dando origem ao descontentamento social e à falta de legitimidade das instituições. As consequências perversas desse modo de vida e produção se reproduzem com muita intensidade, aprofundando as fraturas no tecido social, ampliando em volume e em profundidade as desigualdades engendradas e apontando a impossibilidade de humanização da existência social sob o regime de acumulação vigente imposto.

No modelo neoliberal, a solução para as desigualdades sociais é entendida como responsabilidade de cada indivíduo e de sua capacidade de responder às condições do mercado. Nesse modelo, a principal preocupação é a imposição de uma noção de desenvolvimento, que não visa melhorar as situações de vida da população, visto que está orientado pelas exigências do mercado e de crescimento econômico. Também procura ampliar as condições para que o modelo econômico dominante continue estendendo-se com 
êxito em benefício de poucos, ou seja, da classe dominante que concentra o poder econômico e político, apropriando-se privadamente da maior parte da riqueza socialmente produzida.

Segundo Bihr (1999), o crescimento do desemprego e da instabilidade vem propiciando um sentimento geral de insegurança entre os trabalhadores, agravando a concorrência e as desigualdades, reativando as atitudes de exclusão e segmentação de raça, de sexo e paternalismo. Esse processo de fragmentação vem enfraquecendo efetivamente a classe trabalhadora e provocando rebatimentos no sentimento de pertencer a uma classe, o que dificulta a recomposição de uma representação coletiva em outras bases.

O início do século XXI colocou em evidência as enormes contradições geradas pelo modelo neoliberal. Exclusão social, desigualdades e pobreza continuaram sendo fenômenos de grande magnitude, suscitando a formulação dos Objetivos do Milênio em 2000, pela Organização das Nações Unidas, associados à noção de desenvolvimento. Direcionado aos países em desenvolvimento, esse chamado motivou a criação de compromisso e o estabelecimento de aliança para revitalizar a cooperação internacional, com o propósito de obter melhores resultados na luta contra a pobreza, a fome, a reversão da degradação ambiental, a melhoria das condições de vida, de saúde e educação, entre outras.

No entanto, ao fazer uma primeira avaliação dos resultados em 2005, constatou-se que os avanços haviam sido muito poucos e que os desafios para obter a inclusão social e a equidade continuavam sendo enormes (ONU, 2005). Diante disso, a partir de 2006 as reformulações em torno do desenvolvimento voltaram-se ao centro dos debates internacionais, e foi nesse período que a noção de coesão social ressurgiu como estratégia para enfrentar diversos problemas, como: índices de pobreza e indigência, a desigualdade social extrema e as diversas formas de discriminação e de exclusão social, cuja profundidade e agravamento estavam em relação direta com a dinâmica da economia global.

Durante a primeira década do século XXI, o tema da coesão social sedimentou as propostas dos organismos internacionais e da União Europeia e foi transladado para a América Latina com a intenção de tornar-se o eixo 
orientador das políticas públicas, na tentativa de reiterar a necessidade de um pacto social pelo desenvolvimento regional que fosse capaz de diminuir as desigualdades sociais. Nesse contexto foram gestados os pactos de coalizão entre as classes e os programas de transferência de renda.

A noção de coesão social, segundo os autores Sorj e Maruccelli (2008, p. 247), é fundamentalmente uma referência normativa associada a critérios operacionais em torno de indicadores como emprego, renda, saúde, entre outros, que são selecionados pelo debate público, pelos políticos e pelas tecnocracias.

O termo coesão social tem suas raízes na sociologia francesa do século XIX pela corrente funcionalista representada por Durkheim. Ela sustenta a ideia de que a ordem social é resultado da solidariedade social, argumentando que quanto menor é a divisão social do trabalho, maior é a vinculação do indivíduo com o grupo social. Tal argumento refere-se a uma solidariedade mecânica fundamentada na similitude de sentimentos sociais. A coesão faz parte da solidariedade social necessária para que se reforcem os vínculos.

Essas formulações de Durkheim com respeito à solidariedade são as que fazem eco nas propostas da Comissão Econômica para a América Latina e o Caribe - Cepal. Para a entidade, as fragmentações sociais e o individualismo são fatos confirmados à luz dos alcances e repercussões do capitalismo global. Por isso, tais propostas consideram a coesão social como uma alternativa, diante da necessidade de cooperação entre as instituições e o Estado, para a manutenção da solidariedade, entendida como produto da consciência coletiva e elemento indispensável à satisfação das necessidades sociais.

No entanto, as origens da coesão social têm como base fundamental as sociedades não capitalistas, e sua riqueza conceitual está vinculada ao sentido de pertencimento e identidade de cada membro com o resto da coletividade. Portanto, a coesão social se dá em sociedades que não se regem por princípios utilitaristas, e por isso também torna-se inviável a consideração da noção em outro contexto, o que gera distorções e impossibilidades históricas para a perspectiva que já nasce fadada ao fracasso, haja vista a concepção e operacionalidade das políticas sociais implantadas nesse contexto com noções e fundamentos tão incompatíveis com a sociabilidade vigente. 
As alterações sofridas nos sistemas tradicionais de controle e coesão social afeta significativamente o funcionamento da sociedade, gerando problemas de difícil solução. Vale ressaltar que as novas mudanças ocorridas por processos supranacionais, que alterou a configuração do Estado social e as condições de estruturação da ordem social, baseada no marco normativo de direitos e políticas sociais, não vêm possibilitando mecanismos de redistribuição de riqueza, nem integração dos trabalhadores e muito menos formas de negociação dos interesses em conflito. Tal ideia de coesão social em sociedades desiguais depende da capacidade redistributiva do Estado social.

Para se constituir uma alternativa coerente seria preciso a implementação de políticas que promovessem e gerassem processos amplos de integração e coesão social, que combatessem as desigualdades sociais e seus conflitos na luta pelo direito a uma condição de vida com justiça social por meio do fortalecimento de sujeitos sociais autônomos (Ivo, 2011).

Contudo, vale observar que a configuração da questão social no contexto da globalização vem sendo marcada fortemente pela precarização da força de trabalho, pela feminização da pobreza, pelos retrocessos em relação aos direitos sociais conquistados, consolidando a erosão do Estado social, agudizando as desigualdades sociais e definindo novos contornos e significados no planejamento de políticas sociais, o que interfere sobremaneira no fazer profissional, deslocando a compreensão do problema, a formação e a ação profissional para outros níveis e bases, como ocorre no âmbito do Serviço Social (Faleiros, 1999), intensificando-se um movimento crescente em torno do conservadorismo. Ao privatizar as políticas públicas, o Estado vem reduzindo o campo de intervenção profissional, e a tendência à "refilantropização" (Yazbek, 1993; Iamamoto, 1996) das políticas sociais e dos serviços torna-se uma realidade, que intensifica o processo de individualização dos problemas sociais, ao mesmo tempo que caracteriza a desqualificação profissional no trato da questão social.

A fragmentação das políticas sociais estatais e o aumento de sua prestação por instituições privadas também vêm apontando "para fortes apelos de solidariedade social" e "desprofissionalização" (Iamamoto, 1996, p. 12). Em conjunto e face ao processo de globalização, as profissões e os profissionais vão perdendo espaço de intervenção, baseada em suas expertises, enquanto 
ações voluntárias e filantrópicas passam a fazer parte do eixo estruturante da ação governamental, ampliando tanto as fragmentações das políticas sociais quanto do sujeito.

Nesse sentido, torna-se urgente e crucial buscar explicações para os fenômenos do tempo presente e construir estratégias profissionais que possam interferir na questão social com mais êxito, direcionando a ação para a busca de construção de um projeto societário, no qual o indivíduo, o privado e os interesses pessoais sejam subordinados ao interesse público e ao desenvolvimento da coletividade e à satisfação plena de suas necessidades básicas e de cidadania.

\section{Os sentidos do público e os direitos sociais}

A noção do público como afeto a todos se perdeu nesse contexto neoliberal, cindido por uma exacerbação do individualismo. Os sentidos do público vão se configurando em acepções que contrariam a forma fundamental da construção e existência do público associado a concepção e conquista dos direitos sociais. $\mathrm{O}$ público é sinônimo do que é comum a todos e, assim, se aproxima do coletivo, como algo compartilhado, oposto ao privado, ao que é particular e conforma uma das dicotomias mais fortes, com capacidade de organizar o pensamento social e político moderno (Bobbio, 1985).

Nessa abordagem, o público se torna quase imediatamente político, no qual o institucional obriga a pensar no Estado. O que é público é conhecido e manifesto, pois o que é público possui o atributo da publicidade, e o seu oposto é secreto, oculto ou desconhecido, privado, naquilo que se refere à privacidade, à intimidade, e não à particularidade ou individualidade. O público é sinônimo de acessível, do que está aberto ao coletivo, o que é oposto ao fechado, enclausurado ou excludente (Rabotnik, 2005; Filc, 1997).

Ressalta-se desse sentido do público as preocupações imediatas sobre a gestão institucional e as condições sociais de legitimidade e legitimação de políticas específicas. $O$ interesse provém da convicção de que em toda política o Estado participa na definição da relação e do caráter público ou privado de uma questão. Ou seja, daquela que a define e a conforma ao 
mesmo tempo e daquela sobre quem, para quem e para que a política deve atuar. Condições de vida, relações sociais de gênero e sua transversalidade nas políticas sociais, condições e formas do uso da força de trabalho compõem um sistema no seio do qual seus diferentes elementos se reforçam reciprocamente, de forma mais ou menos intensa, e constituem-se eixos por onde se intensifica a disseminação de desigualdades, abrangendo as principais questões a ser enfrentadas pelas políticas públicas.

Segundo Bihr (2007), os estudos sobre desenvolvimento e desigualdades sociais no interior de determinado Estado não devem ser focalizados nem centrados apenas nas desigualdades de rendimento. Pois no desenvolvimento das políticas vão estabelecendo-se os direitos e deveres, as responsabilidades e atribuições que têm distintos grupos sociais e/ou instituições na intervenção sobre o seu objeto. No que se refere à política social, entende-se que seu objeto são as condições de vida de diferentes classes e grupos sociais. Neste sentido, a política social pode ser definida como o campo de relações e de práticas organizadas pelo Estado. Em seu interior ocorre a disputa pela construção ideológica das condições de vida - e especialmente o trabalho e as necessidades básicas - como assunto público ou como assunto de particulares. Ou seja, como assunto coletivo e parte do interesse comum ou como questão individual.

Por isso a importância e o dever da reconstrução do público, cujo sentido deve ser definido de acordo com o que se identifica com o interesse da coletividade. A dimensão coletiva do público refere-se à orientação que se impõe à sociedade e à direção que se imprime ao Estado e suas ações.

Segundo Danani e Beccaria (2011), as fronteiras do Estado se relacionam com cada ciclo histórico que se identifica com o interesse comum. As autoras argumentam que vem ocorrendo complexidades que se tecem na política pública relacionada com o público e vem se constituindo como um novo padrão de intervenção social cimentado durante a hegemonia neoliberal, fundamentando-se em certas noções de direito. Os direitos fundamentais sociais devem ser utilizados solidariamente por serem revestidos de deveres de solidariedade. Mesmo assim, de acordo com Reis e Fontana (2011), a verdade é que pouco se faz e se avança no desenvolvimento efetivo dos direitos sociais. 
A não efetividade dos direitos sociais vem influindo, em muitos casos, na desigualdade social entre os gêneros. $O$ conceito de desigualdade implica a incapacidade de realizar ou desenvolver algo em todo o seu potencial. A desigualdade de gênero se dá quando os indivíduos aos quais se atribuem determinado gênero não têm acesso a possibilidades sociais de igual nível que os indivíduos de outro gênero.

Por sua vez, a incorporação dos direitos humanos em acordos internacionais vem se tornando uma exigência a fim de garantir a dignidade e a igualdade das populações envolvidas em uma dimensão de relações sociais de gênero. Tal exigência vem ocorrendo pelo reconhecimento de que as condições de vida e trabalho são sexuadas - com exploração diferente e desigual do trabalho feminino. A falta de compromisso com a promoção de direitos é uma característica do mercado e nem sempre do Estado, que necessariamente deve ser submetido ao interesse público. Como isso ocorre no campo do dever ser, a importância da luta por direitos e sua concretização torna-se uma constante no processo civilizatório da humanidade. Dessa forma, os direitos humanos são indivisíveis ao se levar em consideração que é uma forma de proteção dos indivíduos contra a seletividade do Estado (Sassen, 2010).

No entanto, considerando os princípios do neoliberalismo, a função do Estado é apenas negativa, ou seja, de não intervenção. O problema torna-se maior na medida em que as desigualdades sociais a serem enfrentadas se avolumam, ao passo que os recursos financeiros vêm diminuindo e, por conta disso, os direitos sociais e fundamentais acabam não sendo assegurados. Nas reformas que ocorreram nos programas de assistência social existe uma omissão sistemática relacionada à incorporação de uma perspectiva dos direitos (Reis e Fontana, 2011), embora existam programas sociais que objetivam combater a miséria, sendo essa a forma mais efetiva de enfrentar a violação dos direitos humanos.

Dessa maneira, a implementação dos programas de transferência de renda pode constituir-se em alternativas consistentes para alcançar padrões de integração social, garantindo maior coesão social em sociedades desiguais como as da América Latina. Mas essa forma de coesão social é dependente da capacidade redistributiva do Estado social, da configuração 
do mercado, do valor do trabalho, da reprodução social dos trabalhadores e da qualidade das relações sociais.

Esses programas são insuficientes para gerar processos mais amplos de integração social, devido ao seu caráter restritivo, no que se refere aos valores básicos da reprodução, seguridade econômica e social. Ou seja, não gera titularidades de direitos, pois não é um direito social, aprofunda a segmentação da pobreza, não fomenta uma comunidade autônoma de sujeitos sociais, reforçando o controle e a gestão da pobreza pelo Estado (Ivo, 2011).

O contínuo acúmulo do capital através da exploração do trabalho vem sendo conduzido com a imigração ou migração da mão de obra barata. A mão de obra vagueia em busca de oportunidades de trabalho em regiões consideradas desenvolvidas ou em desenvolvimento, mas cujos trabalhadores sobrevivem da precarização do trabalho em condições adversas e impactos ambientais prejudiciais à saúde, além de ter os seus direitos não reconhecidos. $O$ discurso neoliberal de permanente e contínuo crescimento utiliza-se do poder do Estado a fim de acabar com o trabalho organizado e coibir os direitos sociais do trabalhador (Gehlen, 2010).

Esse movimento de espacialização e migração do capital em busca do trabalho excedente incorpora também as mulheres, trabalhadoras rurais, como força de trabalho barata e dócil nos municípios, nos quais vem predominando o discurso dos polos de crescimento econômico. O resultado é computado em uma crescente feminização do proletariado, uma destruição dos sistemas camponeses "tradicionais" de produção, designados como agricultura familiar de produção e uma feminização da subsistência e da pobreza, quando mais de 2 bilhões de pessoas no mundo, cada vez mais amontoadas em cortiços, favelas e guetos de cidades insalubres, tentam sobreviver com menos de dois salários mínimos (Harvey, 2011).

Contudo, no planejamento de políticas públicas e de seus programas sociais não são consideradas na sua formulação e execução a necessidade de processar modificações de forma e de conteúdo capazes de abranger os direitos sociais. Nessa perspectiva, não se assegura a denominada transversalidade de gênero, a fim de valorizar a democratização das relações sociais e dos lugares de gênero. Tal providência poderia evitar um olhar polarizado e 
não relacional sobre o gênero nas políticas públicas. As políticas pretendem viabilizar a igualdade dos direitos, mas não considera a divisão sexual do trabalho precário, a ausência de proteção social e de direitos trabalhistas de forma igualitária, tanto de homens quanto de mulheres (Bandeira, 2012).

Apesar das conquistas dos movimentos feministas, o processo de privatização de algumas dessas políticas, ou sua criação, está ligado à geração de oportunidades de negócios no campo dos direitos sociais e à redução das desigualdades sociais e econômicas. Isso tem levado a uma cuidadosa regulação legal no que se refere aos bens que essa normatização protege. A maior parte dessas políticas de proteção produz potencialmente um efeito de mercantilização (Esping-Andersen, 2006). Essas políticas públicas e sociais estabelecem de forma inequívoca que somente os trabalhadores em relação de dependência devidamente registrados em carteira de trabalho, ou seja, o portador titular do direito, são os destinatários do direito e o objeto do direito. Ao se analisar as condições das relações entre os gêneros percebe-se uma articulação da subordinação da mulher aos mecanismos mais amplos de dominação e exploração de sua força de trabalho aos interesses do capital.

O reconhecimento e a manutenção de uma tensão necessária sobre a igualdade e a diferença entre o indivíduo e as identidades grupais podem descortinar a possibilidade de se encontrar resultados mais democráticos para a emancipação das mulheres em uma sociedade socialmente justa. Tais medidas podem influir e evitar a polarização dos debates atuais. Mas o que se observa é que não existem soluções simples para as questões das desigualdades e das diferenças, dos direitos individuais e das identidades de grupos. Posicionar tais questões como conceitos opostos pode ter como significado perder o ponto de suas interconexões (Scott, 2012).

O enfrentamento da questão das desigualdades exige cada vez mais que se estabeleçam interconexões entre o individual e o coletivo, tornando-se de extrema necessidade o desenvolvimento de políticas sociais que possuam essa concepção e que priorizem em suas ações a consideração das determinações dos problemas a serem combatidos, para que possam planejar, priorizar e desenvolver ações que apresentem impacto na realidade posta e que promovam a mudança social esperada. 


\section{Políticas sociais: a falência da coesão e integração social face às desigualdades}

A Constituição Federal de 1988 corporificou um projeto de democracia social que atendia aos anseios da sociedade na construção de uma nova institucionalidade com justiça social. $\mathrm{O}$ desafio de promover a inclusão social e a redistribuição de renda face o nível de desigualdade existente contou com a organização da sociedade civil em torno das reivindicações sociais e da construção de sistemas de proteção social, estruturados de forma descentralizada e participativa como requisitos fundamentais para a universalização da cidadania.

Foram tomadas medidas de combate à pobreza, porém o impacto na diminuição da desigualdade foi enfraquecido pela negação dos serviços públicos de qualidade em áreas como educação, saúde, saneamento e moradia das populações empobrecidas. A ressignificação do social a partir dos anos de 1990 afastou-se dos sistemas universais dos direitos sociais e se transmutou em programas focalizados de combate à pobreza.

É importante assinalar que essas ações emergem no país em um contexto de profundas transformações societárias, que interferem na "questão social" e trazem na raiz dessas modificações a indagação sobre a compatibilidade (ou não) entre direitos, políticas sociais e as relações que se estabelecem entre Estado, sociedade e mercado nos novos marcos da acumulação capitalista. Contexto no qual a articulação: trabalho, direitos e proteção social pública sofre os impactos das transformações estruturais do capitalismo, que atingem duramente o trabalho assalariado e as relações de trabalho, levando à redefinição dos sistemas de proteção social e da política social em geral. (Yazbek, 2012, p. 305-306)

A assistência social no Brasil foi se desenvolvendo como uma política marcadamente regressiva, permanecendo as "concepções e práticas assistencialistas, clientelistas, 'primeiro-damistas' e patrimonialistas" (Yazbek, 2012, p. 310) e ressurgindo práticas perversas de naturalização da pobreza e de aprofundamento das desigualdades sociais. As condicionalidades e 
contraprestações exigidas dos usuários para a obtenção de permanência nos programas assistenciais são medidas que foram incorporadas no debate acadêmico sobre as políticas públicas e nas práticas profissionais, compondo a sistemática operacional de forma indulgente e compulsória. A execução da política via rede socioassistencial consolidada em práticas solidárias e em prestação de serviços fundamentados em filantropia, voluntariado, benemerência e dever moral afastam a perspectiva da conquista do direito, enquanto criminalizam a pobreza, culpando o indivíduo pela sua condição. Resulta disso o retrocesso confesso ou disfarçado, intensificado por práticas afeitas ao campo da doutrinação religiosa, apresentadas como possibilidades "terapêuticas" ou solução para problemas relacionados à condição de sobrevivência da população despossuída.

Essa forma de realização da política retira do Estado o seu dever, posiciona a ação em campo impróprio para a garantia de direitos, descredencia a expertise profissional construída em torno do objeto da política e reforça a lógica da acumulação dominante. Uma ação contra essa lógica passa necessariamente pela transformação das relações de produção capitalistas que fundamentam a matriz do sistema de desigualdades. Segundo Bihr (2007), para atenuar a lógica cumulativa e reprodutiva nas políticas seria preciso uma coordenação das diferentes políticas setoriais.

As políticas sociais podem ser entendidas como intervenções estatais complexas que regulam os processos de reprodução social por meio de estratégias diferenciadas, operando de forma indireta sobre a relação capital-trabalho. Essas políticas desenvolvem-se como precondição e acondicionamento à acumulação capitalista e cumprem funções econômicas, políticas e culturais amplas e diversas, sem cuja realização não seria evidente a convivência entre capitalismo e democracia.

A política social (no singular) corresponde à forma política da questão social, que se expressa e materializa nas políticas setoriais, incluindo a política de trabalho, que em primeiro lugar delimita os graus de liberdade ou dos alcances da mercantilização da força de trabalho. Nos anos 1990, a política social resultou da incapacidade do mercado de trabalho de cumprir os objetivos de distribuição, tanto das pessoas nos postos de trabalho como dos recursos para a reprodução. A ineficiência das políticas, dos planos, 
dos programas e ações de assistência à pobreza, quando se desenvolvem em um marco de regulamentos que desprotegem o trabalho e afasta-se da distribuição, transcende a capacidade de uso racional dos fundos públicos destinados a essas intervenções.

A dispersão de planos e programas sociais, por sua vez superpostos, vem reproduzindo e produzindo a fragmentação do sujeito. Segundo Danani (2012), o sujeito de tantas intervenções estatais é um, mesmo fragmentado pelos programas do governo, segundo a condição de pobre (novo, estrutural, com emprego, sem emprego, protegido ou informal, aposentado, menor), empregado (pobre, não pobre, protegido, precário), desempregado (sem experiência, não qualificado; qualificado, mas obsoleto ou requalificado).

As políticas sociais assumiram a heterogeneidade social e a devolveram como fragmentos individualizáveis, cujos interesses quase sempre conflitavam entre si (Grassi, 2006). As reformas para liberalizar a economia têm sido acompanhadas por um amplo repertório de reformas sociais que compartem três ideias centrais: focalizar e descentralizar a ação pública, assim como privatizar alguns segmentos dos serviços sociais. As tentativas de focalização da política social incluem a criação de fundos de inversão social, programas de ativação laboral, redes de proteção para os vulneráveis e transferências monetárias condicionadas. Tais ações tiveram como objetivo aliviar as consequências de ajustes econômicos, que incidiram sobre os segmentos mais pobres. Contudo, não vêm alterando as causas estruturais da pobreza que aprofundam as desigualdades sociais.

Dessa forma, o crescimento tem sido errático e não tem alcançado os parâmetros esperados, e os empregos gerados não têm sido suficientes nem de boa qualidade para ter o impacto social esperado diante das desigualdades e do nível de pobreza dos trabalhadores. Nesse contexto, nem a pobreza diminuiu de maneira estrutural, nem a vulnerabilidade social tem sido regulada de maneira efetiva, por meio de esquemas eficientes de seguridade social, nem a exclusão social vem sendo sequer reduzida de maneira significativa (Solano e Cohen, 2011).

Em troca, um velho aspecto não resolvido da questão social na América Latina e outro novo cobram uma grande relevância como possíveis eixos alternativos para articular a ação pública: por uma parte reaparece 
a necessidade de reduzir a desigualdade social, que exige desenvolver um regime de cidadania e de direitos sociais de caráter universal, e não políticas focalizadas. Por outra parte, a necessidade de fazer frente ao grande déficit de coesão social que nem o liberalismo do século XIX nem o desenvolvimentismo do século XX, nem o neoliberalismo dos finais do século passado ou do início do século XXI têm sido eficazes para evitar a marginalização de amplos setores da sociedade, não somente das oportunidades econômicas, mas também dos sistemas de bem-estar social.

\section{Considerações finais}

Estas considerações têm a intenção de abordar o desafio que implica reconhecer a necessidade de discussão em torno dos princípios ideológicos, das premissas teóricas e das ações políticas e econômicas, a partir dos quais seja possível refletir sobre a temática. $\mathrm{O}$ crescimento e a profundidade da desigualdade social, da pobreza, da vulnerabilidade e da exclusão social continuam sendo as principais características sociais tanto do Brasil quanto da América Latina. Essa tendência cresce vertiginosamente com a ascensão de governos de extrema direita, os quais priorizam os interesses privados, do mercado e das elites, enquanto excluem, discriminam, culpabilizam e punem com a perversidade da miséria os segmentos populacionais despossuídos, usurpados, injustiçados e vitimados pelo descaso das autoridades e pelo julgo da sociedade.

Temos pela frente tempos difíceis, restando a possibilidade de resistência no âmbito pessoal e profissional. Somos muitos, somos a maioria, e seremos fortes se buscarmos o mesmo ideal.

\section{Referências}

BANDEIRA, Lourdes. Contribuições à inserção de gênero nas interligações rural urbano no contexto do desenvolvimento sustentável. In: GEHLEN, Vitoria Regia Fernandes; LAINÉ, Pilar Carolina Villar (Orgs.). Costurando com fios invisíveis: a fragmentação do território rural. Recife: Editora Universitária, 2012. 
BIHR, Alain. La nova langue neoliberale: la rhetorique du fetichisme capitaliste. Lausanne: Page Deux, 2007.

Da grande noite à alternativa: o movimento operário europeu em crise. São Paulo: Boitempo, 1999. (Coleção Mundo do Trabalho).

BOBBIO, Norberto. La gran dicotomia: publico-privado. In: Estado, governo, sociedade: por una teoría general de la politica. México: Fondo de Cultura Económica, 1985.

DANANI, Claudia. La reconstrucción de lo público: tres desafíos para reconstruir lo valioso y discutir el sentido In: ANA, Arias et al., Políticas públicas y trabajo social: aportes para la reconstrucción de lo público. Buenos Aires: Espacio Editorial, 2012.

DANANI, Claudia; BECCARIA, Alejandra. La (contra)reforma previsional argentina 20042008: aspectos institucionales y político-culturales del proceso de transformación de la protección. In: DANANI, Claudia; HINTZE, S. (Coords.). Protecciones y desprotecciones: la seguridad social en la Argentina, 1990-2010. Ungs, 2011.

ESPING-ANDERSEN, Gosta, Por que el ingreso básico garantizado es una mala idea? Revista de Trabajo, Buenos Aires, ano 2, n. 3, 2006.

FALEIROS, Vicente. Os desafios do Serviço Social na era da globalização. Serviço Social \& Sociedade, São Paulo, v. 20, n. 61, p. 153-187, 1999.

FILC, Judith. Entre el Parentesco y la Politica. Familia y Ditadura, 1976-1983. Editorial Biblos, Buenos Aires, 1997.

GEHLEN, Vitória Regia Fernandes. Trabalho precário, saúde precarizada: as pessoas trabalhadoras das unidades domésticas de produção de confecções de vestuário e acessórios em Toritama/PE e Americana/Santa Bárbara d’Oeste/SP. Relatório Final de Conclusão de Pós-Doutorado, no Departamento de Medicina Preventiva, Divisão em Saúde Coletiva da Universidade Federal de São Paulo/Unifesp, sob a supervisão da prof. dra. Eleonora Menecucci de Oliveira. São Paulo, 2010.

GRASSI, Estela. Políticas y problemas sociales en la sociedad neoliberal: la otra década infame (I). Buenos Aires: Espacio Ed., 2006.

HARVEY, David. Justice, nature and geography of difference. Nova Jersey: Blackwell Publishing, 2011.

IAMAMOTO, Marilda. O Serviço Social na contemporaneidade: os fundamentos teórico-metodológicos e técnico-operativos do trabalho profissional. In: GIL, Antônio (Org.). Metodologias e técnicas do Serviço Social. Brasília: CNI/Sesi, 1996.

IVO, Anete B. L. Bolsa Família: caminhos de formação da coesão social ou segmentação da pobreza? In: SOLANO, Carlos Barba; COHEN, Nestor (Coords.). Perspectivas criticas sobre la cohesion social: desigualdad y tentativas falidas de integracion social en América Latina. Clacso: Buenos Aires, 2011.

LEFF, Enrique. Discursos sustentáveis. São Paulo: Cortez, 2010.

ONU. Resultados da Cúpula Mundial de 2005. 2005 
PNUD. Programa das Nações Unidas para o Desenvolvimento. Desarrollo sin Pobreza. II Conferencia Regional sobre la pobreza en America latina y el Caribe. Proyecto regional para la superación de la pobreza, Quito, 1990.

RABOTNIK, Nora. En busca de un lugar común: el espacio público en la teoría contemporánea. Unam. México: Instituto de Investigaciones Filosoficas, 2005.

REIS, Jorge Renato dos; FONTANA, Eliane. Direitos fundamentais sociais e a solidariedade: notas introdutórias. In: REIS, Jorge Renato dos; ROGERIO, Gesta Leal (Orgs.). Direitos sociais \& políticas públicas: desafios contemporâneos. Santa Cruz do Sul: Edunisc, 2011.

SCOTT, Joan. Las mujeres y los derechos del hombre: feminismo y sufragio en Francia, 1789-1944. Buenos Aires: Siglo Veintiuno, 2012.

SASSEN, Saskia. Mondialisation et Geographie Global du Travail. In: FALQUET, Jules et al. (Orgs.). Le sexe de la mondialisation: genre, classe, race, et nouvelle division du travail. Paris: Presses de Sciences Po, 2010.

SOLANO, Carlos Barba; COHEN, Nestor. Perspectivas criticas sobre cohesión social: desigualdad y tentativas falidas de integración en América Latina. Buenos Aires: Consejo Latinoamericano de Ciencias Sociales - Clacso, 2011.

SORJ, Bernardo; MARUCCELLI, Danilo. El Desafío Latinoamericano: Cohesión Social y Democracia, São Paulo, Instituto Fernando Henrique Cardoso, 2008.

YAZBEK, Maria Carmelita. Pobreza no Brasil contemporâneo e formas de seu enfrentamento. Serviço Social \& Sociedade, São Paulo, n. 110, p. 288-322, abr./jun., 2012.

. Classes subalternas e assistência social. São Paulo: Cortez, 1993.

\section{Sobre as autoras}

Helena Lúcia Augusto Chaves - Professora da Graduação e da Pós-Graduação em Serviço Social. Líder do Grupo de Estudos e Pesquisas sobre Estado, Política Pública e Sociedade - GEPPS.

E-mail: helena.chaves@gmail.com

VitóRIa RÉgia Fernandes GeHLen - Professora Titular. Pós-doutora pela Universidade de Arquitetura e Planejamento de Marseille-Luminy, França. E-mail:vicgehlen@yahoo.com.br 